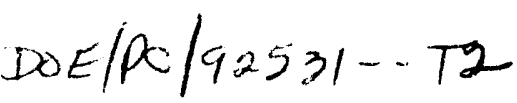

\section{HETERONUCLEAR PROBES OF COAL STRUCTURE AND REACTIVITY}

\author{
John G. Verkade \\ Iowa State University \\ Quarterly Report \\ Due July 31, 1993
}

\section{Introduction}

The main findings in the last quarterly report are:

1. Dibenzothiophene gives up about $27.5 \%$ of its sulfur to refluxing $\mathrm{Bu}_{3} \mathrm{P}$ after 15 hours if a catalytic amount of $\mathrm{Ml}$. No. 6 is present, and 100\% is given up in the presence of $\mathrm{FeCl}_{3}$ as a catalyst.

2. Coal-derived pyrites gave up $83 \%$ of its sulfur in refluxing $\mathrm{Bu}_{3} \mathrm{P}$.

3. Use of a heating mantle to reflux the $\mathrm{Bu}_{3} \mathrm{P}$ causes better sulfur extraction than an oil bath.

4. Replacement of labile protons in Ill. No. 6 by Me groups results in poorer sulfur removal by $\mathrm{Bu}_{3} \mathrm{P}$.

5. The ubiquitous peak at $3 \mathrm{ppm}$ in the solid residue of $\Pi 1$. No. 6 treated with $\mathrm{Bu}_{3} \mathrm{P}, \mathrm{Bu}_{3} \mathrm{PO}$ and $\mathrm{Ph}_{3} \mathrm{P}$ suggests a common product, tentatively believed to be an $-\mathrm{O}_{3} \mathrm{PO}$ moiety.

6. The peak at $3 \mathrm{ppm}$ does not appear to be due to the formation of $\mathrm{H}_{3} \mathrm{PO}_{4}$ in the coal from the extractants, since treatment of Ill. No. 6 with $\mathrm{H}_{3} \mathrm{PO}_{4}$ did not give rise to a $3 \mathrm{ppm}$ peak.

\section{Results}

A. During this past quarter we further addressed the question of which species catalyzes removal of sulfur from coal by $\mathrm{Bu}_{3} \mathrm{P}$.

1. The reaction of anhydrous $\mathrm{FeCl}_{3}$ with $\mathrm{Bu}_{3} \mathrm{P}$ (run 1, Table I) produces in addition to a peak for unreacted $\mathrm{Bu}_{3} \mathrm{P}(-30 \mathrm{ppm})$ a sharp peak at $32 \mathrm{ppm}$. In 
view of the paramagnetism of $\mathrm{FeCl}_{3}$, it would appear that the latter peak could represent a zerovalent $\mathrm{Fe}\left(\mathrm{PBu}_{3}\right)_{\mathbf{x}}$ complex. The oxidation product could then be $\mathrm{Cl}_{2} \mathrm{PBu}_{3}$ or $\mathrm{ClPBu}_{3}{ }^{+} \mathrm{Cl}^{-}$(with its ${ }^{31} \mathrm{P}$ resonance possibly buried beneath the $\mathrm{Bu}_{3} \mathrm{P}$ resonance) but this remains to be seen. It was tempting to assign the $36 \mathrm{ppm}$ peak seen in solid Ill. No. 6 treated with $\mathrm{Bu}_{3} \mathrm{P}$ at room temperature (run 1, Table II) to $\mathrm{Fe}\left(\mathrm{PBu}_{3}\right)_{\mathrm{x}}$, but we currently believe this resonance may be associated with the $\mathrm{HPBu}_{3}{ }^{+}$cation (see section $\mathrm{B}$ ).

2. $\mathrm{FeCl}_{3}$ was added to a reaction of $\mathrm{Bu}_{3} \mathrm{P}$ and Ill. No. 6 (run 2, Table I) to deiermine if sulfur extraction was more efficient. Quantitation of the SPBu in the extract was not possible, however, owing to the paramagnetism of the solution introduced by the addition of the iron. We plan to do a sulfur analysis of the extract.

B. Experimental evidence favoring $\mathrm{HPBu}_{3}{ }^{+}$formation in solid coals treated with $\mathrm{Bu}_{3} \mathrm{P}$ has been observed:

1. Dissolving $\mathrm{PhOH}$ and $\mathrm{PhCO}_{2} \mathrm{H}$ in $\mathrm{Bu}_{3} \mathrm{P}$ (runs 3 and 4, Table I) gives rise to ${ }^{31} \mathrm{P}$ NMR peaks with ${ }^{1} J_{\mathrm{PH}} \cong 450 \mathrm{~Hz}$ at $37 \mathrm{ppm}$ for $\mathrm{HPBu}_{3}{ }^{+-} \mathrm{OPh}$ and $39 \mathrm{ppm}$ for $\mathrm{HPBu}_{3}+{ }^{-} \mathrm{O}_{2} \mathrm{CPh}$.

2. Examination of our ${ }^{31} \mathrm{P}$ NMR spectra of Ill. No. 6 treated with $\mathrm{Bu} \mathrm{u}_{3} \mathrm{P}$ at $\mathrm{room}$ temperature (run 1, Table II) reveals a peak at $36 \mathrm{ppm}$ which is strongly coupled to nearby protons. This result is consistent with protonation of the $\mathrm{Bu}_{3} \mathrm{P}$ since this reaction also occurs under mild conditions in solution.

3. Coals treated with $\mathrm{Bu}_{3} \mathrm{P}$ at higher temperatures (Ill. No. 6, demineralized $\mathrm{Ml}$. No. 6, Penn Seam-see last report and runs 2-7, Table II) display c: solid state $31 \mathrm{P}$ peak in this region ranging from 35 to $32 \mathrm{ppm}$ which is strongly proton coupled.

\section{DISCLAIMER}


4. As expected, Ill. No. 6 in which all but $15 \%$ of the organic matter has been rem.cved leaving $85 \%$ coal-derived pyrites does not show a peak in this region (run 8 , Table II).

5. A Donna Hill coal sample does not reveal a peak in this region (run 9, Table II).

6. Ill. No. 6 samples treated with a variety of other phosphorus reagents $\left(\mathrm{OPBu}_{3}, 85 \% \mathrm{H}_{3} \mathrm{PO}_{4}, \mathrm{P}_{4}, \mathrm{PPh}_{3}, \mathrm{P}\left(\mathrm{NMe}_{2}\right)_{3}\right)$ do not display a ${ }^{31} \mathrm{P}$ NMR peak in this region (see previous report).

7. Ill. No. 6 in which the labile hydrogen groups were methylated with MeI unexpectedly gave a relatively very intense peak at $32 \mathrm{ppm}$ when treated with $\mathrm{Bu}_{3} \mathrm{P}$. Possible explanations are a) methylation was incomplete. b) $\mathrm{H}_{2} \mathrm{O}$ in the coal protonates $\mathrm{Bu}_{3} \mathrm{P}$. Thus the coal is initially treated with $\mathrm{Bu}_{4} \mathrm{~N}^{+-} \mathrm{OH}$ before the $\mathrm{MeI}$ reaction. c) Another phosphorus species resonates in this region. d) Our hypothesis of an $\mathrm{HPBu}_{3}{ }^{+}$species is incorrect.

8. Somewhat puzzling is the observation that pyridine washing of the coal does not remove the $32 \mathrm{ppm}$ peak and in fact does not produce a detectable decrease in its relative intensity. It is curious that this peak is sometimes seen in extracts as a broad hump. We will try a stronger base to see if more complete removal of this peak from the solid can be effected.

9. Ill. No. 6 given a second treatment with fresh $\mathrm{Bu}_{3} \mathrm{P}$ causes the $32 \mathrm{ppm}$ peak to significantly intensify suggesting perhaps deeper penetration of the reagent to break up more deep-seated hydrogen bonding.

C. Additional aspects of the quantitation of sulfur removal from coal using $\mathrm{Bu}_{3} \mathrm{P}$ were addressed.

1. The last report contained a quantitation by ${ }^{31} \mathrm{P}$ NMR of a $\mathrm{Bu}_{3} \mathrm{~F}$-treated demineralized Ill. No. o sample which was anomalously high. We conjectured that this might be associated with simultaneous oxygen removal 
as $\mathrm{OPBu}_{3}$, which we discovered resonates so close to $\mathrm{SPBu}_{3}$ that their ${ }^{31} \mathrm{P}$ NMR peaks overlap in $\mathrm{Bu}_{3} \mathrm{P}$ as a solvent. In pyridine, however, these peaks are well separated (46.8 and $48.8 \mathrm{ppm}$, respectively) and so pyridine was added after the extraction in run 5 in Table 1 . Indeed the peaks are resolved in this mixed solvent mixture and the sulfur analysis (4.35\%) by this technique revealed that $92.0 \%$ of the total sulfur content of the sample $(4.73 \%$, Desert Analytics) was removed as SPBu 3 . Noteworthy is the observation that $\mathrm{Bu}_{3} \mathrm{P}$ de-oxygenates as well as desulfurates coal.

2. Because of the relatively small concentration of the $\mathrm{OPBu}_{3}$ in the extract, infrared spectroscopy in the $v \mathrm{P}=\mathrm{O}$ region was not helpful in detecting this compound.

3. Whereas we can remove $92 \%$ of the sulfur in $\mathrm{Il}$. No. 6 , only $50 \%$ of the sulfur is removed from a Donna Hill sample (run 6, Table I).

4. Washing the solid Ill. No. 6 residue with pyridine decreases the solid state ${ }^{31} \mathrm{P}$ NMR intensity to barely detectable for the SPBu 3 peak, but this is not the case for pentane washing. We have not yet quantitated the amuunt that pyridine washes out.

5. Increasing the temperature and/or duration of treatment of Ill. No. 6 with $\mathrm{Bu}_{3} \mathrm{P}$ increases the ratio of the $50 \mathrm{ppm}$ peak in the solid residue relative to the 32 peak, suggesting that, as expected, the desulfurization reaction is more difficult than the protonation of $\mathrm{Bu}_{3} \mathrm{P}$ to $\mathrm{HPBu}_{3}{ }^{+}$. Interestingly, the ratio of the $32 \mathrm{ppm}$ peak relative to the $3 \mathrm{ppm}$ peak remains about the same suggesting that $(-\mathrm{O})_{3} \mathrm{P}=\mathrm{O}$ formation is also more facile than desulfurization.

D. Experiments aimed at determining the origin of the $3 \mathrm{ppm}{ }^{31} \mathrm{P}$ NMR peak in solid coal samples treated with $\mathrm{Bu}_{3} \mathrm{P}$ and $\mathrm{OPBu}_{3}$ were carried out. 
1. All phosphorus reagents we have lised on Ill. No. 6 so far except $\mathrm{H}_{3} \mathrm{PO}_{4}$ (including $\mathrm{SPBu}_{3}, \mathrm{OPPh}_{3}, \mathrm{SPPh}_{3}, \mathrm{OP}(\mathrm{OBu})_{3}, \mathrm{Ph}_{3} \mathrm{P}$, and $\mathrm{P}\left(\mathrm{NMe}_{2}\right)_{3}$ (runs 11-17, Table II) reveal this peak in the solid residues.

2. Demineralized Ill. No. 6 treated with $\mathrm{Bu}_{3} \mathrm{P}$ and $\mathrm{OPBu}_{3}$ (runs 18 and 19, Table II) also exhibits this peak, although much less intensely in run 19.

3. Ill. No. 6 treated first with $\mathrm{NaOH}$ and then with $\mathrm{OPCl}_{3}$ or $\mathrm{SPCl}_{3}$ also displays this peak (runs 20 and 21, Table II). Because $\mathrm{OPCl}_{3}$ absorbs at $3 \mathrm{ppm}$, run 20 is inconclusive. The peak at $5 \mathrm{ppm}$ in the $\mathrm{OPCl}_{3}$ experiment lies in the region for $\mathrm{OPCl}_{\mathbf{X}}(\mathrm{OR})_{3-\mathrm{x}}$ and the formation of several such compounds could explain its breadth. This peak may also have the same origin in the $\mathrm{SPCl}_{3}$ experiment (run 21, Table II) since $\mathrm{SPCl}_{\mathbf{X}}(\mathrm{OR})_{3-\mathrm{x}}$ compounds resonate at lower field (25-23 ppm).

4. This peak also appears in an Ill. No. 6 sample reacted with $\mathrm{P}_{4}$ (run 22, Table II).

5. This peak is relatively weak in the Penn Seam (NIST) coal (run 7, Table II) and the Donna Hill coal (run 9, Table II) perhaps because of a lower oxygen content (which still must be verified).

6. This peak appears in methylated Ill. No. 6 (run 23, Table II).

7. These results taken together with those in the last report suggest that the peak at $3 \mathrm{ppm}$ is most likely due to an $(-\mathrm{O})_{3} \mathrm{P}=\mathrm{O}$ species, i.e., an organophosphate yet to be identified. If this is so, it means that a strong oxidation reaction occurs which is capable of cleaving $\mathrm{P}-\mathrm{C}$ and $\mathrm{P}=\mathrm{S}$ groups and of converting $\mathrm{P}(0)$ and $\mathrm{P}(\mathrm{III})$ to $\mathrm{P}(\mathrm{V})$ even at room temperature. Interestingly, oxidation of the reagent can also occur, since $\mathrm{OPBu}_{3}$ is detected. It also appears that these oxidation reactions do not require the presence of labile protons, although they may be helpful. 
8. It is somewhat puzzling that coal-derived pyrites treated with $\mathrm{Bu}_{3} \mathrm{P}$ (run 8, Table II) also displays this peak (although it is of decreased intensity) since all but $15 \%$ of the organic material has been removed.

9. This peak is not decreased in intensity by washing the coal (run 10, Table II) with pyridine.

E. On the role of labile hydrogens in desulfurization by $\mathrm{Bu}_{3} \mathrm{P}$.

1. As stated in point 4 of the Introduction, methylated IIl. No. 6 appears to result in less sulfur removal on treatment with $\mathrm{Bu}_{3} \mathrm{P}$ than unmethylated samples. This conclusion appears to be substantiated by the experiment with the Donna Hill coal (run 6, Table I) wherein only $50 \%$ of the sulfur was removed and no peak at $32 \mathrm{ppm}\left(\mathrm{HPBu}_{3}{ }^{+}\right)$appeared in the solid (run 9, Table II).

F. Sulfur removal by other reagents.

1. $\mathrm{P}\left(\mathrm{NMe}_{2}\right)_{3}$ does not remove sulfur since no peak at $80 \mathrm{ppm}$ for $\mathrm{SP}\left(\mathrm{NMe}_{2}\right)_{3}$ was found in run 7, Table I).

2. As expected, extracts of Ill. No. 6 treated with $\mathrm{OPCl}_{3}$ and $\mathrm{SPCl}_{3}$ (runs 8 and 9 , Table I) produced only peaks for excess reagent.

3. A preliminary experiment using white phosphorus and Ill. No. 6 (run 10, Table I) revealed only unreacted $\mathrm{P}_{4}$ at $-470.0 \mathrm{ppm}$ in the extract. This is not unexpected since the reaction products $\mathrm{P}_{4} \mathrm{~S}_{\mathrm{x}}$ and $\mathrm{P}_{4} \mathrm{O}_{\mathrm{x}}$ are not expected to be soluble in toluene. The residue displayed peaks at 3 and $-520 \mathrm{ppm}$ (run 22, Table II). If the latter peak represents $\mathrm{P}_{4}$, it is shifted considerably upfield from the solution value.

G. Shakedown experiments with the HPLC.

1. We have obtained three coal resids from Consol, Inc. and separated them into non-polar and polar fractions using Sep-Pak Plus cartridges (following 
the general procedure of Chao and Suatoni ${ }^{1}$ ) with satisfactory UV spectral verification.

2. We are now in the process of examining these fractions with the HPLC in the hope of separating phenols on a preparative scale for derivatization with 31.P NMR reagents for speciation in conjunction with mass spectrometry.

\section{G. Future Work}

1. If $\mathrm{Fe}\left(\mathrm{PBu}_{3}\right)_{\mathrm{x}}$ is a catalyst for desulfurization, make a catalyst solution by heating $\mathrm{Fe}_{3}(\mathrm{CO})_{9}$ with $\mathrm{Bu}_{3} \mathrm{P}$ or by reducing $\mathrm{FeCl}_{3}$ with $\mathrm{NaNp}$ or $\mathrm{Na}(\mathrm{Hg})$ in the presence of $\mathrm{Bu}_{3} \mathrm{P}$, and then add dibenzothiophene.

2. Try graphite as a desulfurization catalyst.

3. Repeat the dibenzothiophene/active carbon catalyst/Bu $3 \mathrm{P}$ experiment and then add $\mathrm{FeCl}_{3}$ or $\mathrm{Fe}\left(\mathrm{PBu}_{3}\right)_{\mathrm{x}}$ to see if the extra ${ }^{31} \mathrm{P} \mathrm{NMR}$ peaks are sulfur intermediates which then can catalytically form $\mathrm{SPBu}_{3}$.

4. See if $\mathrm{FeS} / \mathrm{Bu}_{3} \mathrm{P} /$ iron catalyst results in sulfur removal.

5. React a $\mathrm{Bu}_{3} \mathrm{P}$-treated coal with $\mathrm{RSSR}, \mathrm{ROOR}$ and $\mathrm{HO}_{2} \mathrm{CCF}_{3}$ to see what happens, if anything, to the 3 and 32 ppm peak.

6. Impregnate IIl. No. 6 with some phenols and/or carboxylic acids to see if the 32 ppm peak grows on $\mathrm{Bu}_{3} \mathrm{P}$ treatment.

7. Try refluxing $\mathrm{Bu}_{3} \mathrm{P}$ treated coal in pyridine and/or a stronger base such as our superbase $\mathrm{P}\left(\mathrm{MeNCH}_{2} \mathrm{CH}_{2}\right)_{3} \mathrm{~N}$ to try to verify that the $32 \mathrm{ppm}$ is due to $\mathrm{HPBu}_{3}{ }^{+}$.

7. Treat a $\mathrm{Bu}_{3} \mathrm{P}$-treated coal with moisture or steam if necessary to see if $\mathrm{H}_{3} \mathrm{PO}_{4}$ is formed from the 3 pom material in the coal.

8. Dry coal with 2,2-dimethoxypropane to see if moisture has an effect on desulfurization and on the formation of the peaks at 32 and $3 \mathrm{ppm}$. 
9. Compare sulfur removal in a coal/ $\mathrm{Bu}_{3} \mathrm{P} /$ pyridine experiment with coal $/ \mathrm{Bu}_{3} \mathrm{P} /$ iron catalyst experiment, both with pyridine washing of the product.

10. Continue with HPLC examination of coal resids.

\section{References}

1. Chao, G. K.-J. and Suatoni, J. J. Chromatog. Sci. 1982, 20, 436. 


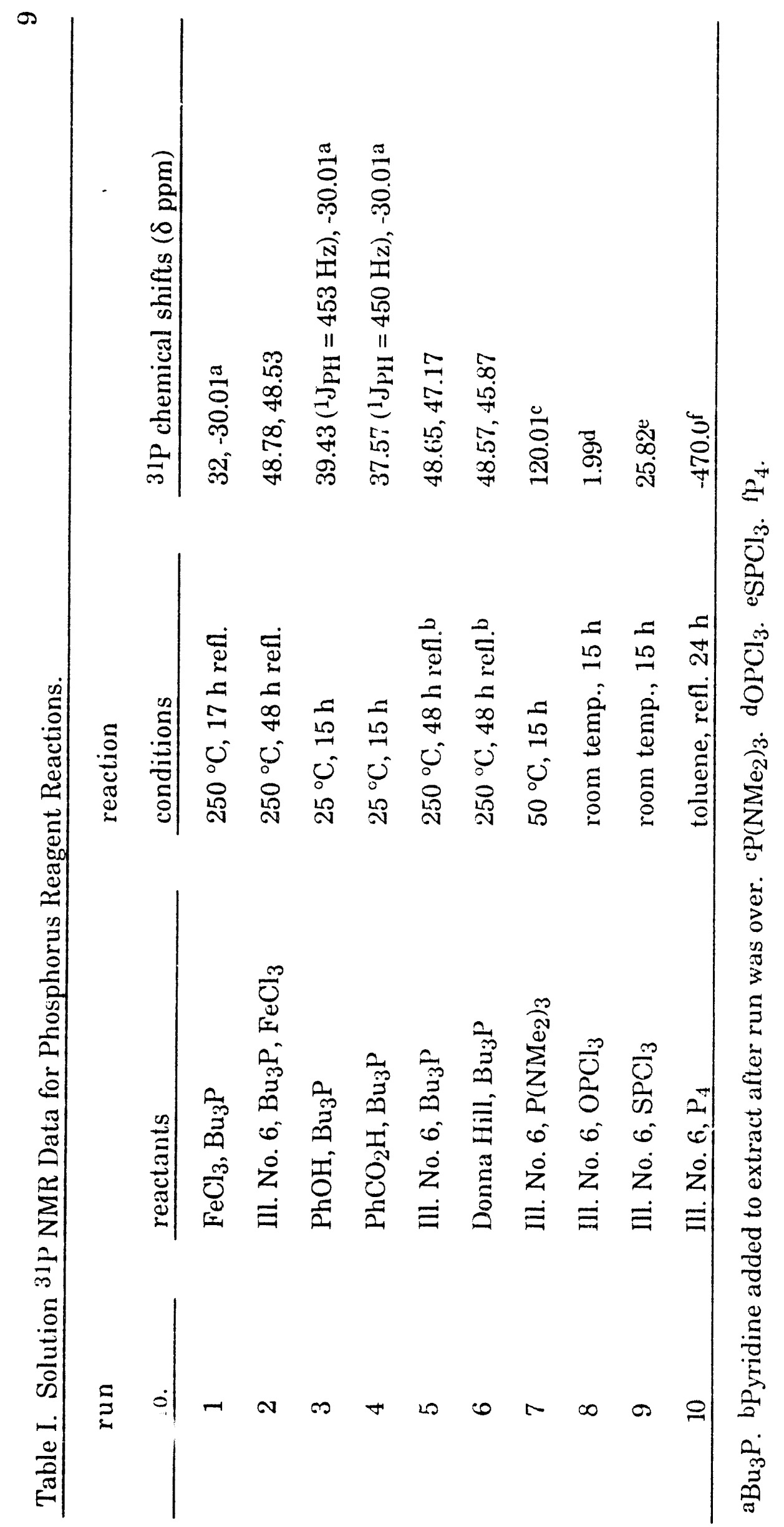




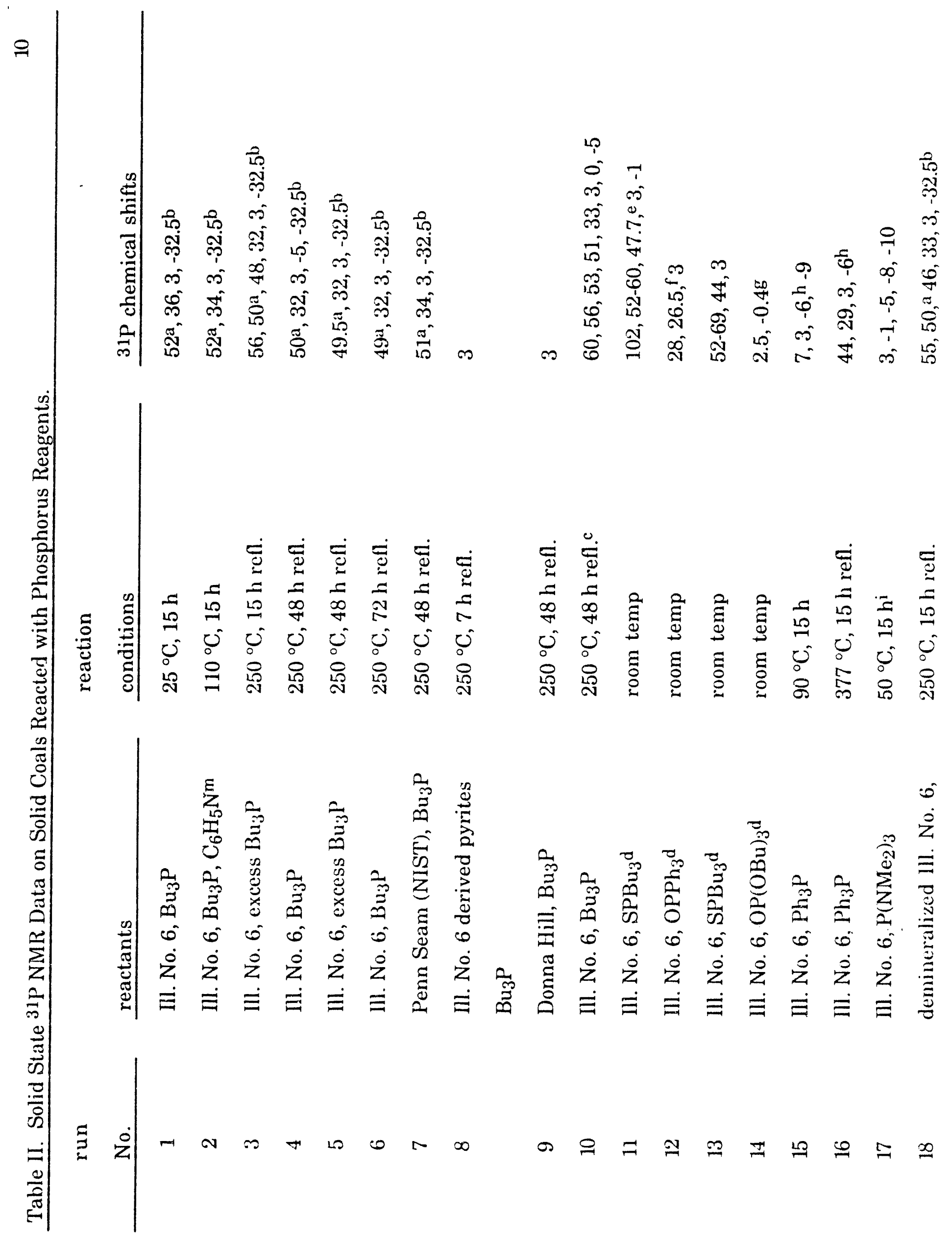




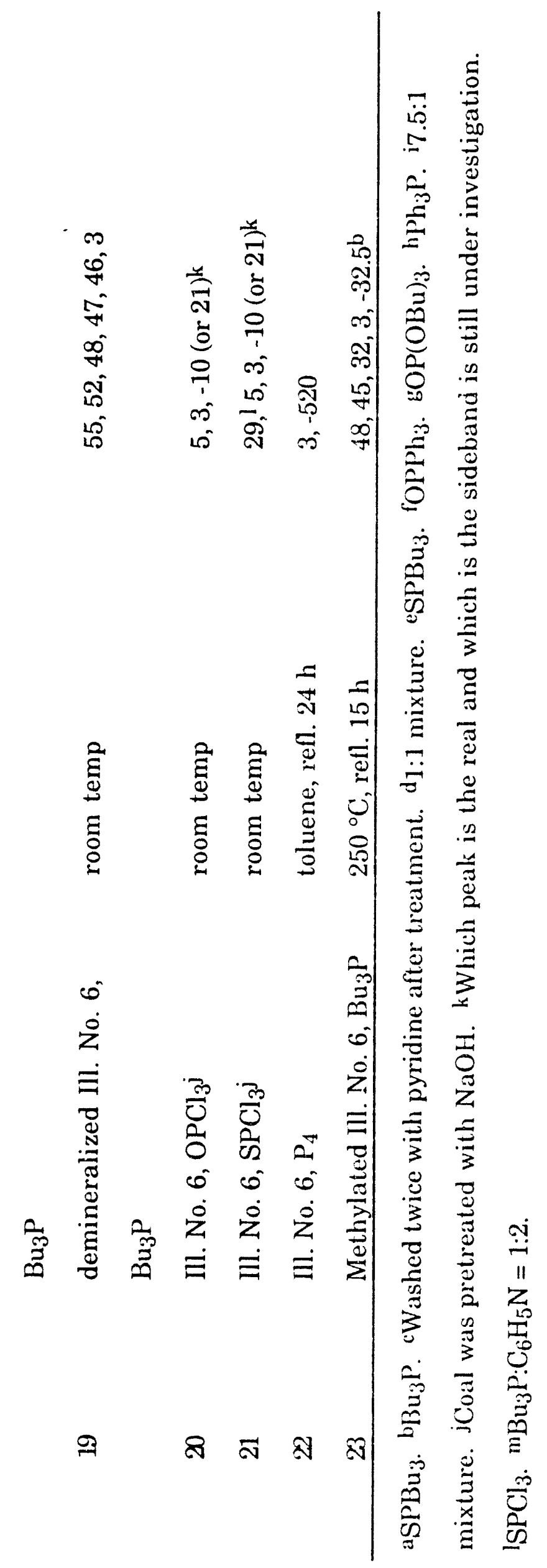



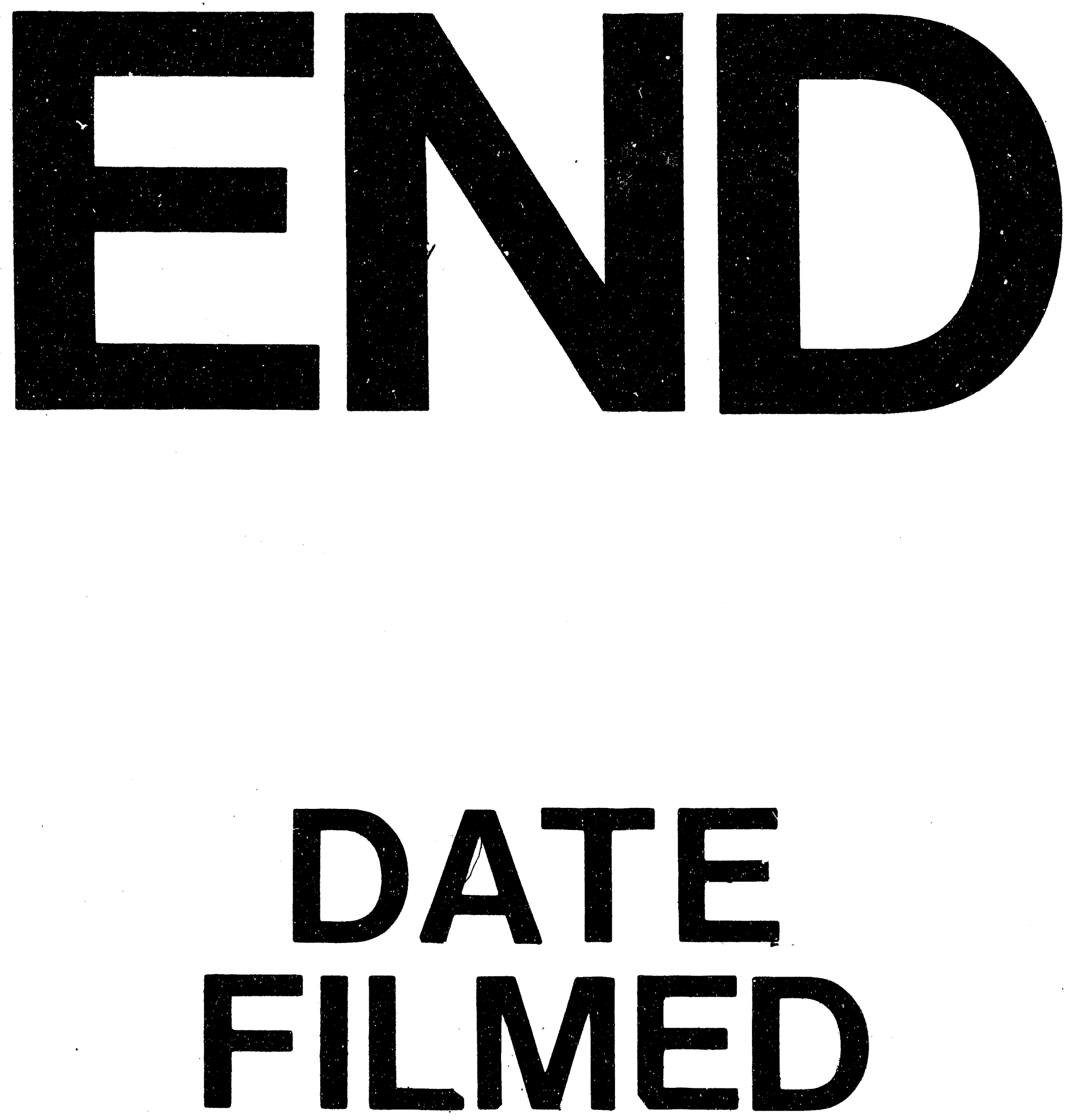

|

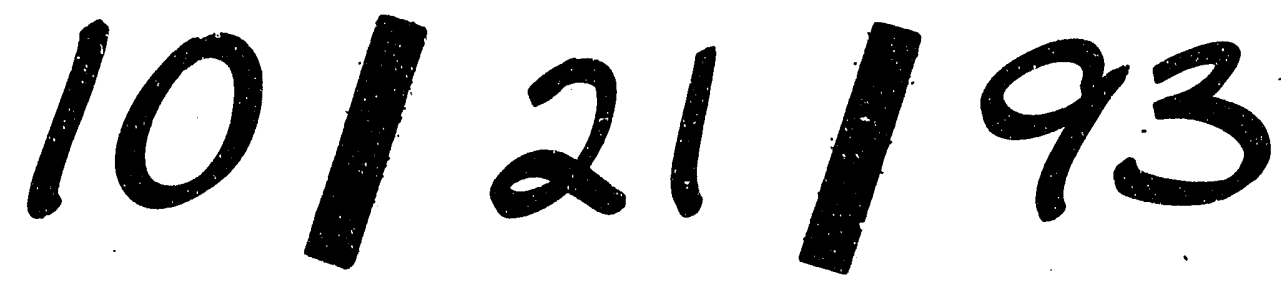

